\title{
Editorial
}

\section{Progress in Photovoltaic Devices and Systems}

\author{
Hongxing Yang, ${ }^{1}$ Hui Shen, ${ }^{2}$ Tao $\mathrm{Xu}^{3}$ and Dimitrios Karamanis ${ }^{4}$ \\ ${ }^{1}$ Renewable Energy Research Group, Department of Building Services Engineering, The Hong Kong Polytechnic University, Kowloon, \\ Hong Kong \\ ${ }^{2}$ Institute for Solar Energy Systems, Sun Yat-Sen University, Guangzhou, China \\ ${ }^{3}$ Department of Chemistry and Biochemistry, Northern Illinois University, 1425 W Lincoln Hwy, DeKalb, IL, USA \\ ${ }^{4}$ Department of Environmental and Natural Resources Management, University of Patras, Agrinio, Greece
}

Correspondence should be addressed to Hongxing Yang; hong-xing.yang@polyu.edu.hk

Received 15 January 2015; Accepted 15 January 2015

Copyright (C) 2015 Hongxing Yang et al. This is an open access article distributed under the Creative Commons Attribution License, which permits unrestricted use, distribution, and reproduction in any medium, provided the original work is properly cited.

Photovoltaic technology is becoming one of the main solutions to the energy issues for the substitution of fossil fuels in the near future. A global cumulative solar photovoltaic capacity of nearly $139 \mathrm{GW}$ was installed in 2013, which became another historic year for solar PV technology. Looking ahead, if distributed PV systems and large scale PV plants do in fact provide the end users with self-sufficiency, it is essential for scientists and engineers all over the world to further exploit solar cells with high efficiency and optimize the PV systems. Thus, related research is needed within current technologies and innovative ideas, including design, modeling, fabrication, and characterization of and modules as well as implementation of PV systems.

Scientific papers in this special issue have covered recent advances in photovoltaic. This issue contains seventeen papers on various aspects of photovoltaic technologies, which fall into following topics:

(1) development, modeling, and reliability improvements of high efficiency solar cells;

(2) building integrated PV systems;

(3) developments in power electronics converters used in PV applications;

(4) distributed generation systems consisting of PV systems and integration with smart grid and smart building;

(5) power converters for photoenergy conversion.

We here would like to express our sincere gratefulness to all authors and referees who contributed a lot to this issue. A brief overview of the papers is presented as follows.
In "Experiment Investigation on Electrical and Thermal Performances of a Semitransparent Photovoltaic/Thermal System with Water Cooling," the authors establish a semitransparent photovoltaic/thermal (SPV/T) system with water cooling for building integrated applications, which yields electrical power and hot water, as well as a natural illumination for the building. The performance of SPV/T system is investigated by adopting the PV efficiency, thermal efficiency, and exergy analysis.

In "Experiment and Simulation Study on the Amorphous Silicon Photovoltaic Walls," the authors test the temperature distribution and the instant power of two amorphous silicon PV walls with and without ventilation and simulate the annual power output at different conditions. They provide some valuable suggestions for the design and construction of PV walls located at low latitudes in China.

In "Integrating Photovoltaic Systems in Power System: Power Quality Impacts and Optimal Planning Challenges," the authors overview the major challenges in photovoltaic based distributed generation (PVDG). The paper evolves the background of PVDG and its impacts on power quality and the maximum allowable penetration level of PVDG connected to a distribution system.

In " $\mathrm{SiO}_{2}$ Antireflection Coatings Fabricated by ElectronBeam Evaporation for Black Monocrystalline Silicon Solar Cells," a double-layer antireflection coatings with the heterostructure of $\mathrm{SiO}_{2} / \mathrm{SiN}_{x}: \mathrm{H}$ is developed enhancing the $\mathrm{EQE}$ in short wavelengths. An absolute conversion efficiency increase of $0.32 \%$ is achieved in solar cell applying this double antireflection coating compared to the conventional single $\mathrm{SiN}_{x}: \mathrm{H}$ coated solar cells. 
In "An Improved Method for Sizing Standalone Photovoltaic Systems Using Generalized Regression Neural Network," an improved approach for sizing standalone PV system (SAPV) is presented, which is based on a combination of an analytical method and a machine learning approach for a generalized artificial neural network (GRNN). The GRNN assists to predict the optimal size of a PV system using the geographical coordinates of the targeted site instead of using mathematical formulas. According to the results, the proposed method can be efficiently used for SAPV sizing whereas the proposed GRNN based model predicts the sizing curves of the PV system accurately with a prediction error of $0.6 \%$. Moreover, hourly meteorological and load demand data are used in this research in order to consider the uncertainty of the solar energy and the load demand.

In "Seismic and Power Generation Performance of UShaped Steel Connected PV-Shear Wall under Lateral Cyclic Loading," a new form of reinforced concrete shear wall integrated with photovoltaic module is proposed in this paper, aiming to apply PV module to the facades of highrise buildings. The seismic behavior, including failure pattern, lateral force-top displacement relationship, and deformation capacity, was investigated. Two main results are demonstrated through the experiment: (1) the U-shaped steel connectors provide enough deformation capacity for the compatibility of the PV module to the shear wall during the whole cyclic test; (2) the electricity generation capacity is effective and stable during this seismic simulation test.

In "A Newton-Based Extremum Seeking MPPT Method for Photovoltaic Systems with Stochastic Perturbations," a novel Newton-based stochastic extremum seeking MPPT method is proposed. Different from conventional gradientbased extremum seeking MPPT algorithm, the convergence rate of the proposed controller can be totally user-assignable rather than determined by unknown power map. The stability and convergence of the proposed controller are rigorously proved. The author further discusses the effects of partial shading and PV module ageing on the proposed controller. Numerical simulations and experiments are conducted to show the effectiveness of the proposed MPPT algorithm.

In "A Review of Solar Photovoltaic Concentrators," the author reviews the different types of PV concentrators, their performance with advantages and disadvantages, concentration ratio, acceptance angle, brief comparison between their efficiencies, and appropriate cooling system.

In "A Simple Approach in Estimating the Effectiveness of Adapting Mirror Concentrator and Tracking Mechanism for PV Arrays in the Tropics," a practical in-field method is conducted in Serdang, Selangor, Malaysia, for the two technologies in comparison to the common fixed flat PV arrays. The data sampling process is measured under stochastic weather characteristics with the main target of calculating the effectiveness of PV power output. The data are monitored, recorded, and analysed in real time via GPRS online monitoring system for 10 consecutive months. Based on the analysis, it is shown that tracking mechanism generates approximately 88 Watts $(9.4 \%)$ compared to the mirror concentrator which generates 144 Watts $(23.4 \%)$ of the cumulative dc power for different array configurations at standard testing condition (STC) references. The significant increase in power generation shows feasibilities of implying both mechanisms for PV generators and thus contributes to additional reference in PV array design.

In "Optimum Availability of Standalone Photovoltaic Power Systems for Remote Housing Electrification," the author discussed the availability of PV systems to determine the optimum availability at which standalone PV systems must be designed. Optimization methods and PV systems software, such as HOMER and PV.MY, were used for this purpose. Six PV systems with six availability levels were analyzed, in terms of wasted energy, cost of energy, battery usage, and power shortages, using real meteorological data. Results show that PV systems with 99\% availability are recommended, because of their high reliability and favorably wasted energy.

In "Superior Antireflection Coating for a Silicon Cell with a Micronanohybrid Structure," a high antireflection silicon solar cell is developed. A novel two-stage metal-assisted etching (MAE) method is proposed for the fabrication of an antireflective layer of a micronanohybrid structure array. The processing time for the etching on an N-type highresistance $(\mathrm{NH})$ silicon wafer can be controlled to around $5 \mathrm{~min}$. The resulting micronanohybrid structure array can achieve an average reflectivity of $1.21 \%$ for a light spectrum of $200-1000 \mathrm{~nm}$. A P-N junction on the fabricated micronanohybrid structure array is formed using a low-cost liquid diffusion source. A high antireflection silicon solar cell with an average efficiency of $13.1 \%$ can be achieved. Compared with a conventional pyramid structure solar cell, the shorted circuit current of the proposed solar cell is increased by $73 \%$. The major advantage of the two-stage MAE process is that a high antireflective silicon substrate can be fabricated costeffectively in a relatively short time. The proposed method is feasible for the mass production of low-cost solar cells.

In "Design and Optimization of Fresnel Lens for High Concentration Photovoltaic System," the author proposed a practical optimization design in which the solar direct light spectrum and multijunction cell response range are taken into account in combination, particularly for the Fresnel concentrators with a high concentration and a small aspect ratio. In addition, the change of refractive index due to temperature variation in outdoor operation conditions is also considered in the design stage. The calculation results show that this novel Fresnel lens achieves an enhancement of energy efficiency of about $10 \%$ compared with conventional Fresnel lens for a given solar spectrum, solar cell response, and corrected sunshine hours of different ambient temperature intervals.

In "Effective Passivation of Large Area Black Silicon Solar Cells by $\mathrm{SiO}_{2} / \mathrm{SiN}_{x}: \mathrm{H}$ Stacks," the performance of black silicon solar cells with various passivation films was characterized. Large area $\left(\mathrm{mm}^{2}\right)$ black silicon was prepared by silver-nanoparticle-assisted etching on pyramidal silicon wafer. The conversion efficiency of black silicon solar cell without passivation is $13.8 \%$. For the $\mathrm{SiO}_{2}$ and $\mathrm{SiN}_{x}: \mathrm{H}$ passivation, the conversion efficiency of black silicon solar cells increases to $16.1 \%$ and $16.5 \%$, respectively. Compared to 
the single film of surface passivation of black silicon solar cells, the $\mathrm{SiO}_{2} / \mathrm{SiN}_{x}: \mathrm{H}$ stacks exhibit the highest efficiency of $17.1 \%$. The investigation of internal quantum efficiency (IQE) suggests that the $\mathrm{SiO}_{2} / \mathrm{SiN}_{x}: \mathrm{H}$ stacks films decrease the Auger recombination through reducing the surface doping concentration and surface state density of the $\mathrm{Si} / \mathrm{SiO}_{2}$ interface, and $\mathrm{SiN}_{\chi}: \mathrm{H}$ layer suppresses the Shockley-Read-Hall (SRH) recombination in the black silicon solar cell, which yields the best electrical performance of $b-S i$ solar cells.

In "Investigating the Impact of Shading Effect on the Characteristics of a Large-Scale Grid-Connected PV Power Plant in Northwest China," a shading simulation model for PV modules is established by the author and its reliability is verified under the standard testing condition (STC) in laboratory. Based on the investigation result of a $20 \mathrm{MWp}$ grid-connected PV plant in northwest China, the typical shading phenomena are classified and analyzed individually, such as power distribution buildings shading and wire poles shading, plants and birds droppings shading, and front-row PV arrays shading. A series of experiments is also conducted on-site to evaluate and compare the impacts of different typical shading forms. Finally, some feasible solutions are proposed to avoid or reduce the shading effect of PV system during operation in such region.

In "Manipulation of $\mathrm{MoSe}_{2}$ Films on $\mathrm{CuIn}(\mathrm{Ga}) \mathrm{Se}_{2}$ Solar Cells during Rapid Thermal Process," the $\mathrm{CuIn}(\mathrm{Ga}) \mathrm{Se}_{2}$ (CIGS) crystalline quality and $\mathrm{MoSe}_{2}$ thickness of films produced by the rapid thermal selenization process under various selenization pressures were investigated. When the selenization pressure increased from $48 \mathrm{~Pa}$ to $1.45 \times 10^{4} \mathrm{~Pa}$, the CIGS films were smooth and uniform with large crystals of varying sizes. However, the $\mathrm{MoSe}_{2}$ thicknesses increased from $50 \mathrm{~nm}$ to $2,109 \mathrm{~nm}$, which created increased contact resistivity for the CIGS/MoSe $/$ /Mo structures. The efficiency of CIGS solar cells could be increased from $1.43 \%$ to $4.62 \%$ due to improvement in the CIGS crystalline quality with increasing selenization pressure from $48 \mathrm{~Pa}$ to $1.02 \times 10^{3} \mathrm{~Pa}$. In addition, the CIGS crystalline quality and $\mathrm{MoSe}_{2}$ thickness were modified by the pressure released valve (PRV) selenization process method. The crystalline qualities of the CIGS films were similarly affected by the selenization pressure at $1.02 \times 10^{3} \mathrm{~Pa}$ in the PRV selenization method and the $\mathrm{MoSe}_{2}$ thicknesses were reduced from 1,219 $\mathrm{nm}$ to $703 \mathrm{~nm}$. A higher efficiency of $5.2 \%$ was achieved with the thinner $\mathrm{MoSe}_{2}$ obtained by using the PRV selenization method.

In "Chaos Synchronization Based Novel Real-Time Intelligent Fault Diagnosis for Photovoltaic Systems," the author used Matlab to simulate the faults in the solar photovoltaic system. The maximum power point tracker (MPPT) is used to keep a stable power supply to the system when the system has faults. The characteristic signal of system fault voltage is captured and recorded, and the dynamic error of the fault voltage signal is extracted by chaos synchronization. Then, the extension engineering is used to implement the fault diagnosis. Finally, the overall fault diagnosis system only needs to capture the voltage signal of the solar photovoltaic system, and the fault type can be diagnosed instantly.

\section{Acknowledgments}

We wish to take this opportunity to thank all contributors and peer reviewers. We would like to thank Dr. Yuanhao Wang from the Renewable Energy Research Group of The Hong Kong Polytechnic University for his coordination of the whole review process.

Hongxing Yang

Hui Shen

Tao Xu

Dimitrios Karamanis 

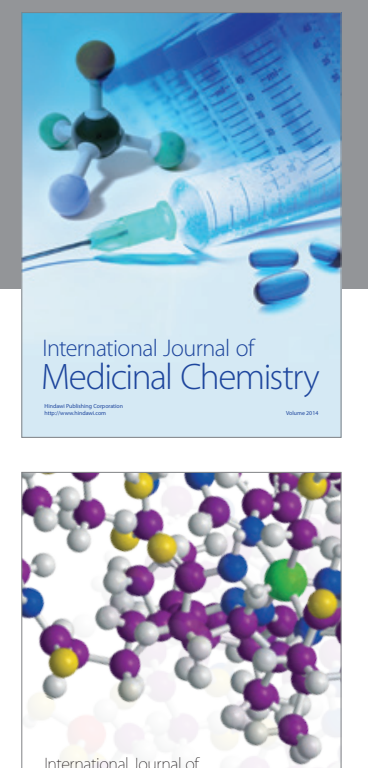

\section{Carbohydrate} Chemistry

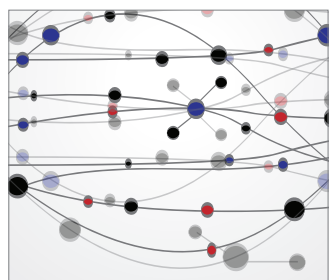

The Scientific World Journal
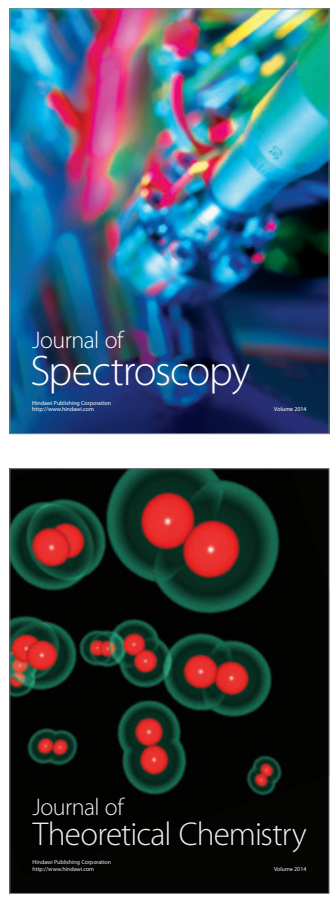
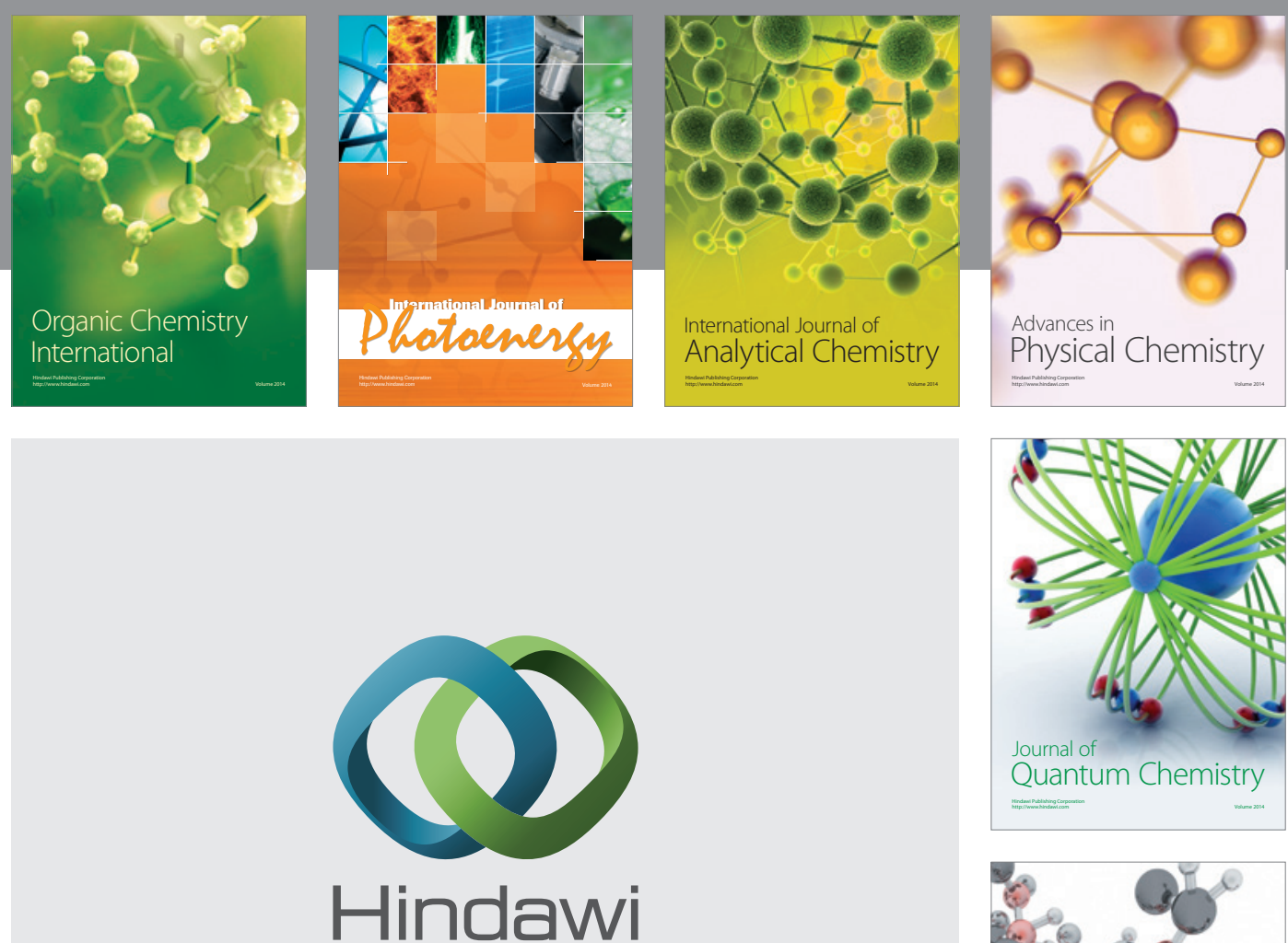

Submit your manuscripts at

http://www.hindawi.com

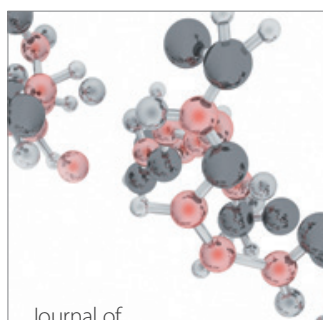

Analytical Methods

in Chemistry

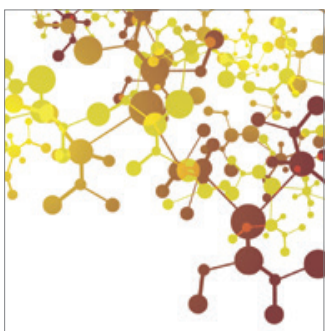

Journal of

Applied Chemistry

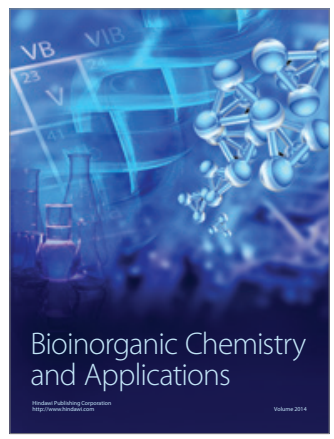

Inorganic Chemistry
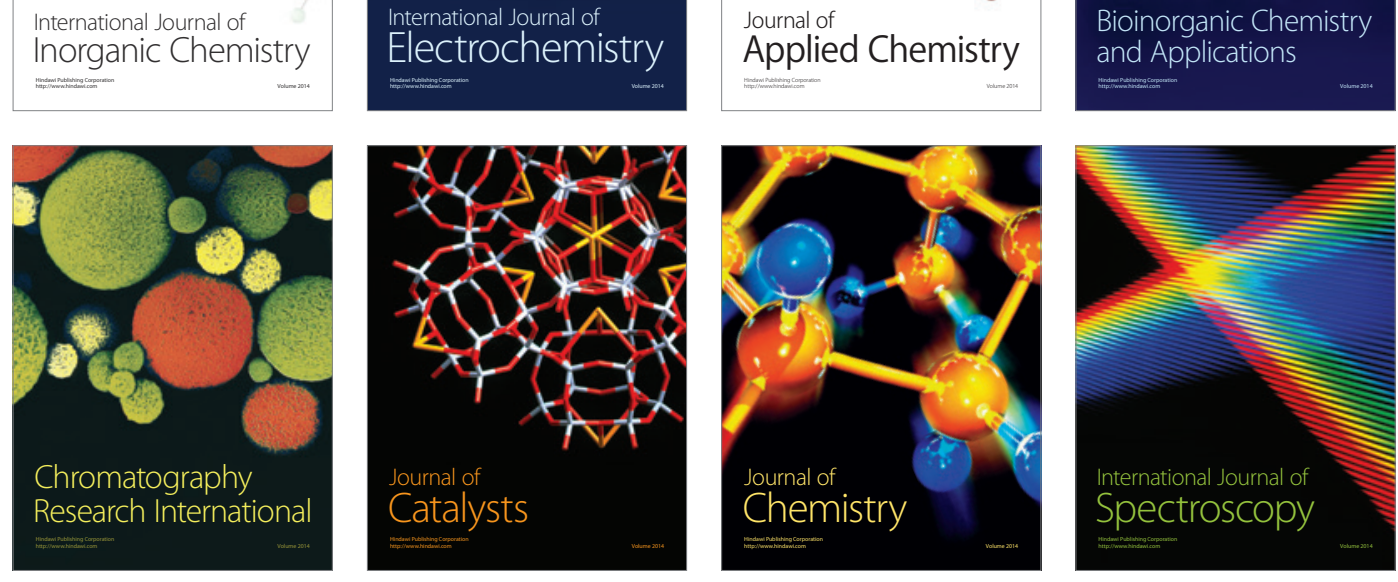